\title{
Phase II trial of capecitabine plus modified cisplatin ( $m X P)$ as first-line therapy in Japanese patients with metastatic gastric cancer (KSCC1104)
}

\author{
Hironaga Satake $^{1} \cdot$ Masaaki Iwatsuki $^{2} \cdot$ Yoshikazu Uenosono $^{3} \cdot$ Takeshi Shiraishi $^{4} \cdot$ Hiroaki Tanioka $^{5}$. \\ Hiroshi Saeki ${ }^{6} \cdot$ Keishi Sugimachi $^{7}$ - Dai Kitagawa ${ }^{8} \cdot$ Mototsugu Shimokawa $^{9} \cdot$ Eiji Oki $^{6} \cdot$ Yasunori Emi $^{10}$.

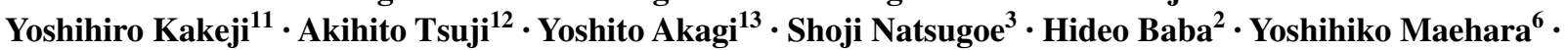 \\ Kyushu Study Group of Clinical Cancer
}

Received: 30 August 2016 / Accepted: 21 November 2016 / Published online: 10 December 2016

(c) The Author(s) 2016. This article is published with open access at Springerlink.com

\begin{abstract}
Purpose Capecitabine plus cisplatin (XP) is a standard therapy for metastatic gastric cancer (mGC). However, while results from previous phase III trials suggested that the cisplatin dosage should be reduced in Japanese patients, no clinical data exist to support this. Here, we conducted a multicenter study to evaluate the efficacy and safety of modified XP (mXP) in Japanese patients with mGC.

Methods Patients with previously untreated $\mathrm{mGC}$ received $\mathrm{mXP}$ (cisplatin $60 \mathrm{mg} / \mathrm{m}^{2}$ on day 1 plus capecitabine $1000 \mathrm{mg} / \mathrm{m}^{2}$ twice daily on days $1-14$ ) every 3 weeks. The primary endpoint was the Response Evaluation Criteria in Solid Tumors-confirmed overall response rate (ORR). A sample size of 40 was planned for a threshold ORR of $30 \%$ and an expected value of $50 \%$, with a one-sided $\alpha$ of 0.05 and a beta of approximately 0.2 .

Results Forty-two patients were enrolled. One patient did not fulfill the eligibility criteria; therefore, a total of 41
\end{abstract}

Yoshihiko Maehara

maehara@surg2.med.kyushu-u.ac.jp

1 Department of Medical Oncology, Kobe City Medical Center General Hospital, Kobe, Japan

2 Department of Gastroenterological Surgery, Graduate School of Medical Sciences, Kumamoto University, Kumamoto, Japan

3 Department of Digestive Surgery, Breast and Thyroid Surgery, Kagoshima University Graduate School of Medical and Dental Sciences, Kagoshima, Japan

4 Department of Medical Oncology, Matsuyama Red Cross Hospital, Matsuyama, Ehime, Japan

5 Department of Medical Oncology, Okayama Rosai Hospital, Okayama, Japan

6 Department of Surgery and Science, Graduate School of Medical Sciences, Kyushu University, Fukuoka, Japan patients were assessed. The results were as follows: complete response in 2 patients, partial response in 16, stable disease in 14 , progressive disease in 8 , and no evaluation in 1. The confirmed ORR was $43.9 \%$ (95\% confidence interval $28.7-59.1 \%$ ). The median progression-free survival and median overall survival were 4.6 and 11.3 months, respectively. The most common grade 3 or 4 adverse events were neutropenia $(37.5 \%)$, anemia $(24.4 \%)$, anorexia $(24.4 \%)$, and nausea (12.2\%).

Conclusions First-line chemotherapy with mXP in Japanese patients with mGC did not reach its primary objective. However, it did show a promising response rate and an acceptable tolerability profile.

Keywords Gastric cancer - Modified XP regimen · Capecitabine $\cdot$ Cisplatin $\cdot$ Chemotherapy

Department of Surgery, Kyushu University Beppu Hospital, Beppu, Japan

8 Department of Gastrointestinal Surgery, Kyushu Central Hospital of the Mutual Aid Association of Public School Teachers, Fukuoka, Japan

9 Clinical Research Institute, Cancer Biostatistics Laboratory, National Kyushu Cancer Center, Fukuoka, Japan

10 Department of Surgery, Saiseikai Fukuoka General Hospital, Fukuoka, Japan

11 Division of Gastrointestinal Surgery, Department of Surgery, Graduate School of Medicine, Kobe University, Kobe, Japan

12 Department of Clinical Oncology, Faculty of Medicine, Kagawa University, Kagawa, Japan

13 Department of Surgery, Kurume University School of Medicine, Kurume, Japan 


\section{Introduction}

Gastric cancer is the third leading cause of cancer-associated deaths worldwide [1]. Once the disease becomes inoperable, the prognosis for gastric cancer is exceptionally poor. Most cases of inoperable advanced or metastatic gastric cancer (mGC) remain incurable, and median survival is only 11-14 months, even for patients who undergo chemotherapy [2-4].

The combination of fluoropyrimidine and cisplatin is used worldwide for the treatment of mGC [2, 3]. Capecitabine is an oral fluoropyrimidine that is activated in tumor tissue via a three-step enzymatic conversion that culminates in the generation of thymidine phosphorylase [5]. Capecitabine has been shown to be effective in the treatment of gastric cancer; it is also administered as a combination treatment with cisplatin [6, 7]. Capecitabine plus cisplatin (XP) is regarded as a standard therapy for mGC. Globally, doses in the XP regimen consist of capecitabine $\left(1000 \mathrm{mg} / \mathrm{m}^{2}\right.$ twice daily on days $\left.1-14\right)$ plus cisplatin $\left(80 \mathrm{mg} / \mathrm{m}^{2}\right.$ on day 1$)$ every 3 weeks [8]. For Japanese patients, however, there has been no phase I trial of the combination XP regimen in a 3-week cycle. The pivotal Avastin in Gastric Cancer (AVAGAST) trial, a global phase III study that focused on the benefit of adding bevacizumab to the XP regimen for advanced gastric cancer [9], included 94 Japanese patients who received XP alone. The median progression-free survival (PFS) in this Japanese XP group was equivalent to that of the overall chemotherapy group (5.7 vs. 5.3 months). In the AVAGAST trial, however, the cisplatin dose was reduced in the second cycle from 80 to $60 \mathrm{mg} / \mathrm{m}^{2}$ in about $50 \%$ of the Japanese patients. Furthermore, a cisplatin dose reduction due to adverse events was reported in $79.8 \%$ of Japanese patients during the treatment course [10]. Accordingly, a more feasible dose for Japanese patients is anticipated.

Here, we develop a modified XP (mXP) regimen to reduce toxicity while maintaining efficacy in the treatment of mGC. This study was designed to evaluate the efficacy and safety of $\mathrm{mXP}$ in the clinical care of Japanese patients with mGC, including elderly patients. To confirm the safety of mXP regimens in both academic and community oncology practices, we performed this study across multiple institutions in both academic and community practice settings.

\section{Materials and methods}

\section{Eligibility criteria}

Eligibility criteria were: age $>20$ years; histologically confirmed human epidermal growth factor receptor type 2 negative unresectable or recurrent gastric cancer; Eastern Cooperative Oncology Group (ECOG) performance status $<2$; one or more measurable tumor lesions according to the Response Evaluation Criteria in Solid Tumors (RECIST) guidelines [11]; estimated life expectancy $\geq 3$ months; and adequate organ function, as defined by hemoglobin $(\mathrm{Hb})$ $\geq 9 \mathrm{~g} / \mathrm{dL}$, white blood cell count $\geq 3000 / \mathrm{mm}^{3} \leq 12,000 /$ $\mathrm{mm}^{3}$, absolute neutrophil count (ANC) $\geq 1500 / \mathrm{mm}^{3}$, platelet count $\geq 100,000 / \mathrm{mm}^{3}$, total bilirubin $\leq 2.0 \mathrm{mg} / \mathrm{dL}$, serum transaminase level $\leq 100 \mathrm{U} / \mathrm{L}$, serum creatinine level $\leq 1.50 \mathrm{mg} / \mathrm{dL}$, and creatinine clearance $\geq 50 \mathrm{~mL} / \mathrm{min}$. Adjuvant chemotherapy was allowed if $>6$ months had elapsed between the end of the therapy and the registration. Exclusion criteria were as follows: contraindication to any drug contained in the chemotherapy regimen; evidence of prior history of platinum administration; insufficient oral intake; synchronous or previous malignancy other than carcinoma in situ; severe comorbidities; active bleeding from the digestive tract; uncontrolled infection; severe mental disorder; pregnancy or lactation; and brain metastasis.

This trial was carried out in accordance with the Helsinki Declaration and Good Clinical Practice guidelines and was approved by the institutional review boards of all participating institutions. All patients were required to give written informed consent before entering the study. The Kyushu Study Group of Clinical Cancer (KSCC) Data Center conducted the data management, central monitoring, and statistical analysis.

\section{Study design and treatment}

Protocol treatment was defined as chemotherapy consisting of capecitabine and cisplatin. Patients received capecitabine $\left(1000 \mathrm{mg} / \mathrm{m}^{2}\right.$ twice daily on days $\left.1-14\right)$ plus cisplatin $\left(60 \mathrm{mg} / \mathrm{m}^{2}\right.$ on day 1) every 3 weeks. Following capecitabine administration on days 1-14, there was a 1-week rest period. Treatment was repeated until disease progression, unacceptable toxicity, or withdrawal of consent.

To prevent chemotherapy-induced nausea and vomiting, the 5-hydroxytryptamine-3 receptor antagonist dexamethasone [9.9 mg, intravenous (i.v.)] and the selective neurokinin-1 neurotransmitter receptor antagonist aprepitant $[125 \mathrm{mg}$, per os (p.o)] were administered $1.5 \mathrm{~h}$ before chemotherapy on day 1 . Aprepitant $(80 \mathrm{mg}$ p.o.) and dexamethasone ( $8 \mathrm{mg}$ p.o.) were administered on days 2 and 3 . Prophylactic use of granulocyte colony-stimulating factor was not allowed.

The dose was modified for each patient based on hematologic or non-hematologic toxicity. Treatment was delayed if, on the planned day of treatment, laboratory results included the following: ANC $<1500 / \mathrm{mm}^{3}$, platelets $<75,000 / \mathrm{mm}^{3}, \mathrm{Hb}<9 \mathrm{~g} / \mathrm{dL}$, serum transaminase $>100 \mathrm{U} / \mathrm{L}$, total bilirubin $>2.0 \mathrm{mg} / \mathrm{dL}$, serum creatinine $>1.50 \mathrm{mg} /$ 
$\mathrm{dL}$, or if symptomatic toxicity was present. In the event of National Cancer Institute Common Terminology for Adverse Events (NCI-CTC) grade 4 neutropenia/leucopenia, or grade 3 or higher febrile neutropenia/thrombocytopenia/diarrhea/stomatitis, the capecitabine and cisplatin doses were reduced by 1 dose level starting at the next cycle. Capecitabine and cisplatin doses could be reduced by $400 \mathrm{mg} / \mathrm{m}^{2} /$ day and $10 \mathrm{mg} / \mathrm{m}^{2}$, respectively, for each level. Patients who could not tolerate cisplatin could continue to receive capecitabine monotherapy until disease progression or intolerable toxicity. Capecitabine could be reduced by 2 dose levels, but treatment was discontinued if subsequent reduction was indicated. In the event of grade 4 non-hematologic toxicities, treatment was definitively interrupted.

\section{Study assessment}

Pretreatment evaluation included: medical history; physical examination; complete blood cell count and serum chemistry tests; esophagogastroduodenoscopy; and chest, abdominal, and pelvic computed tomography (CT) scans. Complete blood cell counts with differential and serum biochemistry analyses were repeated at each treatment cycle. Response was assessed radiologically every 2 cycles or when progression was suspected. The same radiologic method used to document disease at baseline was used at subsequent assessments. No independent radiologic review was performed. All adverse events experienced during the study were recorded and graded according to the NCI-CTC guidelines (CTCAE version 4.0).

\section{Endpoints and statistical analysis}

The primary endpoint was overall response rate (ORR) according to the Response Evaluation Criteria in Solid Tumors (RECIST) criteria v1.0. Complete response (CR) and partial response (PR) were confirmed by reassessment on CT scans after at least another 4 weeks. Secondary endpoints included PFS, overall survival (OS), time to treatment failure (TTF), time to failure of strategy (TFS), and safety.

The previous phase III study showed that the ORR of XP for gastric cancer was 46\% [8]. Furthermore, in the AVAGAST study, the ORR in the Japanese XP group was $49.2 \%$ [10]. Therefore, we calculated that 35 patients were required to achieve $80 \%$ power to reject the null hypothesis of ORR $\leq 30 \%$, assuming that the true ORR was $50 \%$, using a one-sided $\alpha$ of 0.05 based on the normal approximation for binomial distribution. Taking into consideration the dropout rate, the number of patients enrolled was 40 .

The survival curve was estimated using the KaplanMeier method, and 95\% CI was estimated using the Brookmeyer and Crowley method. Safety and efficacy analyses were both conducted on a full analysis set (FAS) population, which was defined as all patients enrolled in the study that fulfilled the eligibility criteria and received chemotherapy at least once. PFS was defined as the time from the date of enrollment to the first documentation of disease progression or death. OS was determined from the date of enrollment to the date of death or last confirmed date of survival. TTF was defined as the time from the date of enrollment to the discontinuation of protocol treatment, first documentation of disease progression, or death. TFS was defined as the time from the date of enrollment to second-line chemotherapy initiation, first documentation of disease progression, or death. All statistical analyses were performed with SAS version 9.4 (SAS Institute, Cary, NC).

This trial was registered with University Hospital Medical Information Network (No. UMIN:000006668).

\section{Results}

\section{Patient characteristics}

Forty-two patients were enrolled in this study from November 2011 to October 2013. Among them, 1 patient was excluded from all analyses due to failure to fulfill the eligibility criteria. Accordingly, 41 patients were included in the FAS population and analyzed (Table 1). Fifteen patients (36.3\%) had undergone resection of the primary tumor: total gastrectomy in 9 patients and other surgeries in 6 . Five patients had received prior neoadjuvant and/or adjuvant chemotherapy, while 36 patients had received no prior chemotherapy.

\section{Treatment}

At the data cutoff date, treatment was ongoing in just 2 patients. The major reasons for discontinuation of treatment in the remaining 39 patients were disease progression in 21 (54\%) patients, adverse events in $11(28 \%)$, surgical resection for the primary lesion or radiotherapy in $4(10 \%)$, and other reasons in $3(8 \%)$. Adverse events that required treatment discontinuation included digestive symptoms (anorexia/nausea/vomiting; $n=4)$, fatigue $(n=2)$, depressed level of consciousness $(n=1)$, hand-foot syndrome (HFS; $n=1)$, severe neutropenia $(n=1)$, renal impairment $(n=1)$, and a thromboembolic event $(n=1)$. The median relative dose intensity (RDI) was $83.7 \%$ [95\% confidence interval (CI) 50.6-101.0\%] for cisplatin and 70.1\% (95\% CI 48.6-109.2\%) for capecitabine.

\section{Efficacy}

The ORR was $43.9 \%$ (95\% CI 28.7-59.1\%), with CR in 2 patients and PR in 16 patients (Table 2). The disease control 
Table 1 Patient characteristics $(n=41)$

\begin{tabular}{|c|c|c|}
\hline Variable & $n$ & $(\%)$ \\
\hline \multicolumn{3}{|l|}{ Age (years) } \\
\hline Median (range) & $64(50-81)$ & \\
\hline \multicolumn{3}{|l|}{ Sex } \\
\hline Male & 34 & 82.9 \\
\hline Female & 7 & 17.1 \\
\hline \multicolumn{3}{|l|}{ ECOG PS } \\
\hline 0 & 33 & 80.5 \\
\hline 1 & 8 & 19.5 \\
\hline \multicolumn{3}{|l|}{ Primary tumor location } \\
\hline $\mathrm{U}$ & 12 & 29.3 \\
\hline $\mathrm{M}$ & 19 & 46.3 \\
\hline $\mathrm{L}$ & 10 & 24.4 \\
\hline \multicolumn{3}{|l|}{ Histology of primary tumor } \\
\hline Well & 18 & 43.9 \\
\hline Poorly & 22 & 53.7 \\
\hline Other & 1 & 2.4 \\
\hline \multicolumn{3}{|l|}{ HER2 status } \\
\hline IHC 0/1+ & 37 & 90.2 \\
\hline IHC $2+/$ FISH negative & 4 & 9.8 \\
\hline \multicolumn{3}{|l|}{ Disease status } \\
\hline Advanced & 28 & 68.3 \\
\hline Recurrent & 13 & 31.7 \\
\hline \multicolumn{3}{|l|}{ Sites of metastasis } \\
\hline Liver & 17 & 41.5 \\
\hline Lungs & 1 & 2.4 \\
\hline Lymph node & 32 & 78.0 \\
\hline Peritoneum & 12 & 29.3 \\
\hline Other & 7 & 17.0 \\
\hline
\end{tabular}

ECOG Eastern Cooperative Oncology Group, PS performance status, $H E R 2$ human epidermal growth factor receptor type 2, IHC immunohistochemistry, FISH fluorescence in situ hybridization

rate was $78.0 \%$ (95\% CI $65.4-90.7 \%)$. With a median follow-up period of 9.6 months (range 1.9-30.2 months), median PFS, median TFS, median TTF, and median OS were 4.6 months (95\% CI 3.9-6.5), 4.4 months (95\% CI 2.5-5.3), 4.0 months (95\% CI 2.3-4.9) and 11.3 months (95\% CI 7.7-14.3), respectively (Figs. 1, 2).

\section{Safety}

The worst toxicities experienced throughout the treatment period are listed in Table 3. The most common grade 3 or higher hematologic toxicities were neutropenia (37.5\%) and anemia $(24.4 \%)$. The most common grade 3 or higher non-hematologic toxicities were anorexia (24.4\%) and nausea $(12.2 \%)$. HFS occurred in $46.3 \%$ of patients; grade 3 or
Table 2 Treatment response rate $(n=41)$

\begin{tabular}{lrc}
\hline Variable & $n$ & $\%(95 \% \mathrm{CI})$ \\
\hline Complete response & 2 & $4.9(0.1-16.5)$ \\
Partial response & 16 & $39.0(24.2-55.5)$ \\
Stable disease & 14 & $34.1(20.1-50.6)$ \\
Progressive disease & 8 & $19.5(8.8-34.9)$ \\
Not evaluated & 1 & $2.4(0.0-12.9)$ \\
Overall response rate & 18 & $43.9(28.7-59.1)$ \\
Disease control rate & 32 & $78.9(65.4-90.7)$ \\
\hline
\end{tabular}

CI confidence interval

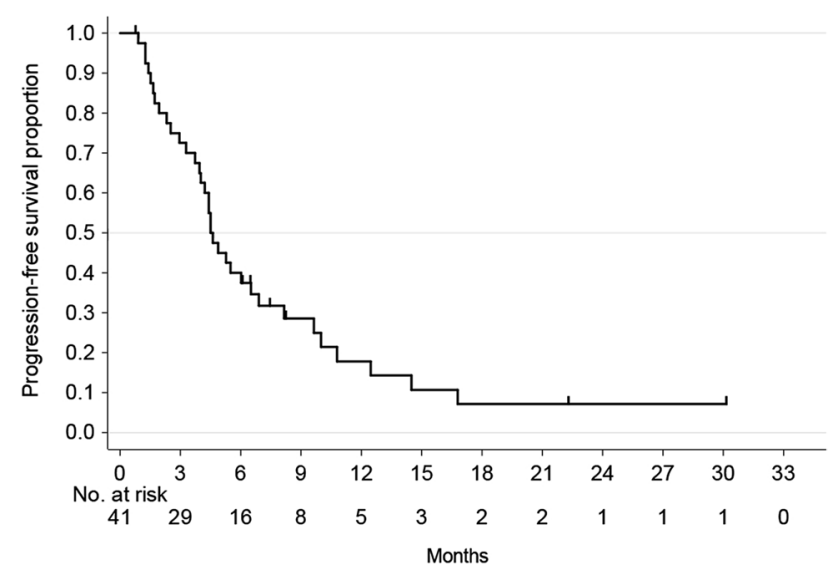

Fig. 1 Progression-free survival $(n=41)$

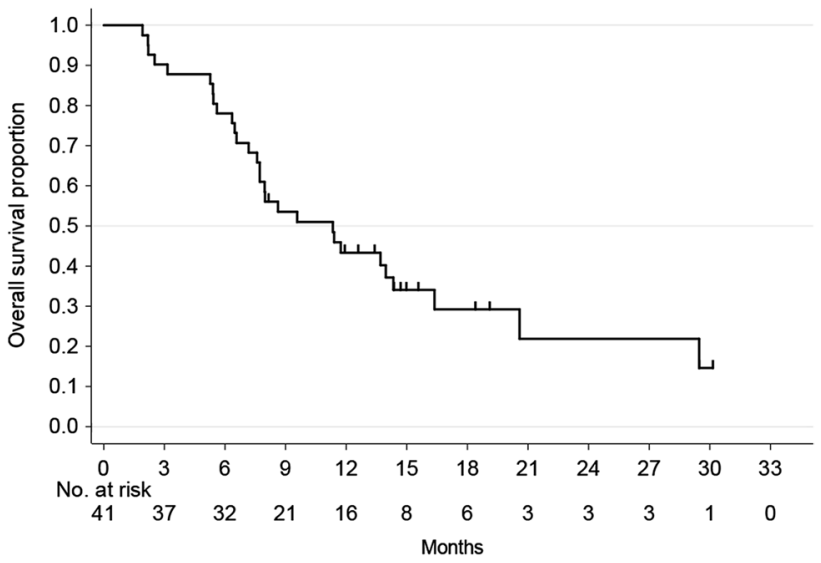

Fig. 2 Overall survival $(n=41)$

higher HFS occurred in $7.3 \%$ of patients. Febrile neutropenia occurred in 2 patients, but they recovered with conservative therapy and the protocol treatment could be continued. There were no treatment-related deaths. 
Table 3 Maximum toxicity per patient $(n=41)$

\begin{tabular}{|c|c|c|c|c|c|c|}
\hline \multirow[t]{2}{*}{ Adverse event } & \multicolumn{6}{|c|}{ NCI-CTC grade } \\
\hline & 1 & 2 & 3 & 4 & All (\%) & $3-4(\%)$ \\
\hline \multicolumn{7}{|l|}{ Hematologic, $n$} \\
\hline Leukopenia & 8 & 15 & 7 & 0 & 73.2 & 17.1 \\
\hline Neutropenia & 8 & 7 & 13 & 2 & 75.0 & 37.5 \\
\hline Anemia & 13 & 17 & 10 & 0 & 97.6 & 24.4 \\
\hline Thrombocytopenia & 20 & 3 & 1 & 0 & 58.5 & 2.4 \\
\hline \multicolumn{7}{|l|}{ Non-hematologic, $n$} \\
\hline Alopecia & 3 & 0 & - & - & 7.3 & 0 \\
\hline Anorexia & 13 & 8 & 10 & 0 & 75.6 & 24.4 \\
\hline Depressed level of consciousness & 0 & 0 & 1 & 0 & 2.4 & 2.4 \\
\hline Diarrhea & 4 & 2 & 0 & 0 & 14.6 & 0 \\
\hline Dysgeusia & 6 & 4 & - & - & 24.4 & 0 \\
\hline Fatigue & 10 & 14 & 4 & 0 & 68.3 & 9.8 \\
\hline Febrile neutropenia & - & - & 2 & 0 & 4.9 & 4.9 \\
\hline Hand-foot syndrome & 10 & 6 & 3 & 0 & 46.3 & 7.3 \\
\hline Nausea & 10 & 10 & 5 & 0 & 61.0 & 12.2 \\
\hline Peripheral sensory neuropathy & 6 & 3 & 0 & 0 & 22.0 & 0 \\
\hline Renal impairment & 7 & 0 & 0 & 0 & 17.1 & 0 \\
\hline Skin hyperpigmentation & 13 & 0 & - & - & 31.7 & 0 \\
\hline Stomatitis & 10 & 3 & 1 & 0 & 34.1 & 2.4 \\
\hline Thromboembolic event & 0 & 0 & 1 & 0 & 2.4 & 2.4 \\
\hline Vomiting & 5 & 2 & 3 & 0 & 24.4 & 7.3 \\
\hline
\end{tabular}

NCI-CTC National Cancer Institute Common Toxicity Criteria

\section{Discussion}

In this study, we found that the mXP regimen was active and tolerable as first-line chemotherapy in patients with mGC. Previous studies of the XP regimen in patients with mGC reported an ORR of $35-37.4 \%$ with a median PFS of 5.3-5.5 months and a median OS of 10.1-11.1 months $[9,12]$. The efficacy in our study was equivalent to that of these previous studies, with an ORR of $43.9 \%$, median PFS of 4.6 months, and median OS of 11.3 months, although the actual ORR was lower than the expected ORR (50\%). To our knowledge, this is the first multicenter prospective study of capecitabine plus cisplatin as first-line chemotherapy for Japanese patients with mGC.

One reason for the lower than expected efficacy may be the comparatively lower dose intensity of capecitabine and the lower dose of cisplatin. In the AVAGAST study, the RDI of capecitabine was $80 \%$ in the Japanese XP group and $87 \%$ in the overall XP group. In contrast, with the mXP regimen, the RDI of capecitabine was $70.1 \%$. As a result, the frequency of HFS in this study was lower than that in a previous report (57 vs. 46\%) [10]. Lotions are currently recommended to improve moisturization and patients receive instructions on how to prevent adverse effects, such as heat exposure, and to reduce friction; therefore, the dose intensity is expected to be higher. This study shows that the $\mathrm{mXP}$ regimen maintained an RDI of cisplatin of 83.7 versus $71 \%$ in both the Japanese XP group and overall XP group in the AVAGAST study. This means that $16.7 \mathrm{mg} / \mathrm{m}^{2} /$ week of cisplatin was actually administered in the mXP regimen, while $18.9 \mathrm{mg} / \mathrm{m}^{2} /$ week was administered in the AVAGAST trial. Furthermore, treatment discontinuation due to adverse events occurred in only 6-7\% in the Japanese XP group in the AVAGAST study, versus $28 \%$ in the present study. We planned the $\mathrm{mXP}$ regimen by modifying the cisplatin dose to improve dose intensity and ensure safety in the cohort of Japanese patients. However, the lower dose intensity of capecitabine, the lower dose of cisplatin, and treatment discontinuation due to adverse events may explain why this study did not reach the expected ORR. Table 4 shows a historical comparison of first-line chemotherapies consisting of capecitabine plus cisplatin for mGC.

Compared with previous reports, severe toxicities were not commonly observed with the mXP regimen in the current study. In the AVAGAST study, grade 3 or higher adverse events in a Japanese XP group included neutropenia $(48 \%)$, anorexia (29\%), nausea (19\%), and anemia (11\%) [10]. In the present study, lower incidence rates of these adverse advents were observed: neutropenia, $37.5 \%$; anorexia, $24.4 \%$; nausea, $12.2 \%$; and anemia, $2.4 \%$. 
Table 4 Historical comparison of first-line chemotherapy consisting of capecitabine plus cisplatin for metastatic gastric cancer

\begin{tabular}{llll}
\hline & Current study $(n=41)$ & AVAGAST, Japanese XP group $(n=94)$ & AVAGAST, overall XP group $(n=387)$ \\
\hline Median OS (months) (95\% CI) & $11.3(7.7-14.3)$ & $14.2(10.9-18.8)$ & $10.1(9.0-11.3)$ \\
Median PFS (months) (95\% CI) & $4.6(3.9-6.5)$ & $5.7(5.3-7.0)$ & $5.3(4.4-5.6)$ \\
Response rate (\%) & 43.9 & 49.2 & 37.4 \\
RDI of cisplatin (\%) & 83.7 & 71 & 71 \\
RDI of capecitabine (\%) & 70.1 & 80 & 87.0 \\
\hline
\end{tabular}

AVAGAST Avastin in Gastric Cancer, $O S$ overall survival, $P F S$ progression-free survival, $R D I$ relative dose intensity

Moreover, about $50 \%$ of the Japanese patients in the AVAGAST study required a cisplatin dose reduction during the second treatment cycle, and $79.8 \%$ of patients required a cisplatin dose reduction due to adverse events at some point during the treatment course [10]. In contrast, grade 3 or higher toxicities during the first treatment cycle in the present study were neutropenia $(n=10)$, anemia $(n=2)$, thrombocytopenia $(n=1)$, anorexia $(n=4)$, nausea/vomiting $(n=3)$, stomatitis $(n=1)$, fatigue $(n=1)$, and febrile neutropenia $(n=2)$, while only 15 patients $(37 \%)$ required a dose reduction during the second treatment cycle. In other words, the safety profile of the mXP regimen appears promising. On the contrary, mild bone suppression might mean that the dose of cisplatin is insufficient.

Several limitations of our study warrant mention. We did not perform a phase I study to determine the dose of cisplatin in the XP regimen for Japanese patients with gastric cancer, so the optimum cisplatin dose remains unclear. We set the cisplatin dose in the current study at $60 \mathrm{mg} / \mathrm{m}^{2}$ based on the S-1 plus cisplatin (SP) regimen [3, 13] and a previous phase 2 study of XP for gastric cancer [7]. The optimal dose of capecitabine, when administered as a monotherapy, is $1250 \mathrm{mg} / \mathrm{m}^{2}$ twice daily, on days $1-14$, every 3 weeks [14]. Additionally, a previous phase 2 study administered capecitabine at $1250 \mathrm{mg} / \mathrm{m}^{2}$, twice daily, on days $1-14$ plus cisplatin at $60 \mathrm{mg} / \mathrm{m}^{2}$ i.v. on day 1, repeated every 3 weeks [7]. However, the standard XP regimen for $\mathrm{mGC}$ now consists of capecitabine $(1000 \mathrm{mg} /$ $\mathrm{m}^{2}$, twice daily, on days $\left.1-14\right)$ plus cisplatin $\left(80 \mathrm{mg} / \mathrm{m}^{2}\right.$ on day 1) every 3 weeks [8]. This means that the standard XP regimen consists of a decreased capecitabine dose and an increased cisplatin dose, compared with previous studies. When combined with cisplatin, both S-1 and capecitabine are orally administered with fluoropyrimidines to ensure efficacy in the treatment of gastric cancer. However, the recommended dose of cisplatin in a combination treatment depends on the combination: $60 \mathrm{mg} / \mathrm{m}^{2}$ cisplatin for the SP regimen and $80 \mathrm{mg} / \mathrm{m}^{2}$ cisplatin for the XP regimen. Furthermore, the present study did not reach its primary objective. This might mean that the anti-tumor effect of cisplatin in the XP regimen is more dose-dependent than that of cisplatin in the SP regimen, so we should have discussed the modification of cisplatin dose further. Preclinical studies demonstrated the indirect role of cisplatin as a modulator for fluorouracil (5-FU), in addition to its direct effect as an effector $[15,16]$. S-1 is a novel oral fluoropyrimidine consisting of a 5-FU prodrug, tegafur, a dihydropyrimidine dehydrogenase inhibitor, 5-chloro-2,4-dihydroxypyridine, and the orotate phosphoribosyl-transferase inhibitor, potassium oxonate, which suppresses the gastrointestinal toxicity of tegafur [17]. In contrast, capecitabine is an oral fluoropyrimidine that is metabolized primarily in the liver and converted in tumor tissues to 5-FU by the enzyme thymidine phosphorylase, which is present in higher concentrations in tumor cells than in normal cells [18]. The differences between $\mathrm{S}-1$ and capecitabine may affect the role of cisplatin in each regimen. In the present study, only 1 patient did not experience grade 3 or higher toxicities during treatment; in other words, this patient might have been disadvantaged by the $\mathrm{mXP}$ regimen because the cisplatin reduction may have been unnecessary.

In conclusion, although the present study did not reach its primary objective, the mXP regiment showed promising efficacy and an acceptable tolerability profile in clinical practice. The modified XP regimen is a treatment option for patients with mGC.

Acknowledgements The authors would like to thank the patients and families who participated in this study. The enclosed material was presented in part at the 2015 Gastrointestinal Cancers Symposium, San Francisco, January 15-17, 2015. This research was supported by the Kyushu Study Group of Clinical Cancer (KSCC).

Funding This study was conducted by the KSCC and Clinical Research Support Center (CReS) Kyushu. Chugai Pharmaceutical Co. and Bristol-Myers Squibb provided an unrestricted contribution to CReS Kyushu.

\section{Compliance with ethical standards}

Conflict of interest Yoshikazu Uenosono received a laboratory fund donation from Chugai Pharmaceutical Co., Ltd. Eiji Oki received a speaker honorarium from Chugai Pharmaceutical Co., Ltd. Yasunori Emi received a speaker honorarium from Chugai Pharmaceutical Co., Ltd. Yoshihiro Kakeji received a speaker honorarium from Chugai Pharmaceutical Co., Ltd. Akihito Tsuji received a speaker honorarium from Chugai Pharmaceutical Co., Ltd. Yoshito Akagi received a 
speaker honorarium and research grants from Chugai Pharmaceutical Co., Ltd. Shoji Natugoe received a laboratory fund donation from Chugai Pharmaceutical Co., Ltd. Hideo Baba received a speaker honorarium and research grants from Chugai Pharmaceutical Co., Ltd. Yoshihiko Maehara received a speaker honorarium, research grants, and researcher and laboratory fund donations from Chugai Pharmaceutical Co., Ltd. All remaining authors have declared no conflict of interest.

Open Access This article is distributed under the terms of the Creative Commons Attribution 4.0 International License (http://creativecommons.org/licenses/by/4.0/), which permits unrestricted use, distribution, and reproduction in any medium, provided you give appropriate credit to the original author(s) and the source, provide a link to the Creative Commons license, and indicate if changes were made.

\section{References}

1. Ferlay J, Soerjomataram I, Dikshit R, Eser S, Mathers C, Rebelo M, Parkin DM, Forman D, Bray F (2015) Cancer incidence and mortality worldwide: sources, methods and major patterns in GLOBOCAN 2012. Int J Cancer 136(5):E359-E386. doi:10.1002/ijc. 29210

2. Cunningham D, Starling N, Rao S, Iveson T, Nicolson $M$, Coxon F, Middleton G, Daniel F, Oates J, Norman AR, Upper Gastrointestinal Clinical Studies Group of the National Cancer Research Institute of the United Kingdom (2008) Capecitabine and oxaliplatin for advanced esophagogastric cancer. N Engl J Med 358(1):36-46. doi:10.1056/NEJMoa073149

3. Koizumi W, Narahara H, Hara T, Takagane A, Akiya T, Takagi M, Miyashita K, Nishizaki T, Kobayashi O, Takiyama W, Toh Y, Nagaie T, Takagi S, Yamamura Y, Yanaoka K, Orita H, Takeuchi M (2008) S-1 plus cisplatin versus S-1 alone for first-line treatment of advanced gastric cancer (SPIRITS trial): a phase III trial. Lancet Oncol 9(3):215-221. doi:10.1016/ S1470-2045(08)70035-4

4. Yamada Y, Higuchi K, Nishikawa K, Gotoh M, Fuse N, Sugimoto N, Nishina T, Amagai K, Chin K, Niwa Y, Tsuji A, Imamura H, Tsuda M, Yasui H, Fujii H, Yamaguchi K, Yasui H, Hironaka S, Shimada K, Miwa H, Hamada C, Hyodo I (2015) Phase III study comparing oxaliplatin plus S-1 with cisplatin plus S-1 in chemotherapy-naive patients with advanced gastric cancer. Ann Oncol 26(1):141-148. doi:10.1093/annonc/mdu472

5. Miwa M, Ura M, Nishida M, Sawada N, Ishikawa T, Mori K, Shimma N, Umeda I, Ishitsuka H (1998) Design of a novel oral fluoropyrimidine carbamate, capecitabine, which generates 5-fluorouracil selectively in tumours by enzymes concentrated in human liver and cancer tissue. Eur J Cancer 34(8):1274-1281

6. Kang HJ, Chang HM, Kim TW, Ryu MH, Sohn HJ, Yook JH, Oh ST, Kim BS, Lee JS, Kang YK (2005) Phase II study of capecitabine and cisplatin as first-line combination therapy in patients with gastric cancer recurrent after fluoropyrimidine-based adjuvant chemotherapy. Br J Cancer 92(2):246-251. doi:10.1038/ sj.bjc. 6602336

7. Kim TW, Kang YK, Ahn JH, Chang HM, Yook JH, Oh ST, Kim BS, Lee JS (2002) Phase II study of capecitabine plus cisplatin as first-line chemotherapy in advanced gastric cancer. Ann Oncol 13(12):1893-1898

8. Kang YK, Kang WK, Shin DB, Chen J, Xiong J, Wang J, Lichinitser M, Guan Z, Khasanov R, Zheng L, Philco-Salas M, Suarez T, Santamaria J, Forster G, McCloud PI (2009) Capecitabine/ cisplatin versus 5-fluorouracil/cisplatin as first-line therapy in patients with advanced gastric cancer: a randomised phase III noninferiority trial. Ann Oncol 20(4):666-673. doi:10.1093/ annonc/mdn717

9. Ohtsu A, Shah MA, Van Cutsem E, Rha SY, Sawaki A, Park SR, Lim HY, Yamada Y, Wu J, Langer B, Starnawski M, Kang YK (2011) Bevacizumab in combination with chemotherapy as first-line therapy in advanced gastric cancer: a randomized, double-blind, placebo-controlled phase III study. J Clin Oncol 29(30):3968-3976. doi:10.1200/JCO.2011.36.2236

10. Yamaguchi K, Sawaki A, Doi T, Satoh T, Yamada Y, Omuro Y, Nishina T, Boku N, Chin K, Hamamoto Y, Takiuchi H, Komatsu Y, Saji S, Koizumi W, Miyata Y, Sato A, Baba E, Tamura T, Abe T, Ohtsu A (2013) Efficacy and safety of capecitabine plus cisplatin in Japanese patients with advanced or metastatic gastric cancer: subset analyses of the AVAGAST study and the ToGA study. Gastric Cancer 16(2):175-182. doi:10.1007/s10120-012-0167-0

11. Therasse P, Arbuck SG, Eisenhauer EA, Wanders J, Kaplan RS, Rubinstein L, Verweij J, Van Glabbeke M, van Oosterom AT, Christian MC, Gwyther SG (2000) New guidelines to evaluate the response to treatment in solid tumors. European Organization for Research and Treatment of Cancer, National Cancer Institute of the United States, National Cancer Institute of Canada. J Natl Cancer Inst 92(3):205-216

12. Bang YJ, Van Cutsem E, Feyereislova A, Chung HC, Shen L, Sawaki A, Lordick F, Ohtsu A, Omuro Y, Satoh T, Aprile G, Kulikov E, Hill J, Lehle M, Ruschoff J, Kang YK (2010) Trastuzumab in combination with chemotherapy versus chemotherapy alone for treatment of HER2-positive advanced gastric or gastro-oesophageal junction cancer (ToGA): a phase 3, openlabel, randomised controlled trial. Lancet 376(9742):687-697. doi:10.1016/S0140-6736(10)61121-X

13. Ryu MH, Baba E, Lee KH, Park YI, Boku N, Hyodo I, Nam BH, Esaki T, Yoo C, Ryoo BY, Song EK, Cho SH, Kang WK, Yang SH, Zang DY, Shin DB, Park SR, Shinozaki K, Takano T, Kang YK, Investigators SOSs (2015) Comparison of two different S-1 plus cisplatin dosing schedules as first-line chemotherapy for metastatic and/or recurrent gastric cancer: a multicenter, randomized phase III trial (SOS). Ann Oncol 26(10):2097-2101. doi:10.1093/annonc/mdv316

14. Mackean M, Planting A, Twelves C, Schellens J, Allman D, Osterwalder B, Reigner B, Griffin T, Kaye S, Verweij J (1998) Phase I and pharmacologic study of intermittent twice-daily oral therapy with capecitabine in patients with advanced and/or metastatic cancer. J Clin Oncol 16(9):2977-2985

15. Araki H, Fukushima M, Kamiyama Y, Shirasaka T (2000) Effect of consecutive lower-dose cisplatin in enhancement of 5-fluorouracil cytotoxicity in experimental tumor cells in vivo. Cancer Lett 160(2):185-191

16. Omura K, Misaki T, Hashimoto T, Kanehira E, Watanabe T, Ishida F, Watanabe Y, Shirasaka T (1995) Changes in folate concentration in Yoshida sarcoma after administration of leucovorin or cisplatin. Cancer Chemother Pharmacol 35(3):183-187. doi:10.1007/BF00686545

17. Shirasaka T, Shimamato Y, Ohshimo H, Yamaguchi M, Kato T, Yonekura K, Fukushima M (1996) Development of a novel form of an oral 5-fluorouracil derivative (S-1) directed to the potentiation of the tumor selective cytotoxicity of 5-fluorouracil by two biochemical modulators. Anticancer Drugs 7(5):548-557

18. Ishikawa T, Utoh M, Sawada N, Nishida M, Fukase Y, Sekiguchi F, Ishitsuka H (1998) Tumor selective delivery of 5-fluorouracil by capecitabine, a new oral fluoropyrimidine carbamate, in human cancer xenografts. Biochem Pharmacol 55(7):1091-1097 